\title{
Specific serology for emerging human coronaviruses by protein microarray
}

C Reusken (chantal.reusken@rivm.nl)1,2 H Mou $^{1,3}$, G J Godeke ${ }^{1,2}$, L van der Hoek ${ }^{4}$, B Meyer ${ }^{5}$, M A Müller5, B Haagmans ${ }^{6}$,

R de Sousa ${ }^{2}$, N Schuurman ${ }^{3}$, U Dittmer ${ }^{7}$, P Rottier ${ }^{3}$, A Osterhaus $^{6}$, C Drosten $^{5}$, B J Bosch ${ }^{3}$, M Koopmans $^{2,6}$

1. These authors contributed equally to this work

2. Centre for Infectious Disease Control, Division Virology, National Institute for Public Health and the Environment, Bilthoven, the Netherlands

3. Department of Infectious Diseases and Immunology, Utrecht University, Faculty of Veterinary Medicine, Utrecht, the Netherlands

4. Laboratory of Experimental Virology, Department of Medical Microbiology, Center for Infection and Immunity Amsterdam, Academic Medical Center, University of Amsterdam, Amsterdam, the Netherlands

5. Institute of Virology, University of Bonn Medical Centre, Bonn, Germany

6. Department of Viroscience, Erasmus Medical Centre, Rotterdam, the Netherlands

7. Institute for Virology, University Hospital Essen, University of Duisburg-Essen, Essen, Germany

Citation style for this article:

Reusken C, Mou H, Godeke GJ, van der Hoek L, Meyer B, Müller MA, Haagmans B, de Sousa R, Schuurman N, Dittmer U, Rottier P, Osterhaus A, Drosten C, Bosch BJ, Koopmans M. Specific serology for emerging human coronaviruses by protein microarray. Euro Surveill. 2013;18(14):pii=20441. Available online: http://www. eurosurveillance.org/ViewArticle.aspx?Articleld=20441

Article submitted on 29 March 2013 / published on 04 April 2013

We present a serological assay for the specific detection of IgM and IgG antibodies against the emerging human coronavirus hCoV-EMC and the SARS-CoV based on protein microarray technology. The assay uses the $\mathrm{S}_{1}$ receptor-binding subunit of the spike protein of hCoV-EMC and SARS-CoV as antigens. The assay has been validated extensively using putative cross-reacting sera of patient cohorts exposed to the four common hCoVs and sera from convalescent patients infected with hCoV-EMC or SARS-CoV.

\section{Background}

In 2012, a novel human betacoronavirus (hCoV-EMC) emerged in the Middle East [1]. At the end of March 2013, 17 confirmed cases of hCoV-EMC infection had been reported to the World Health Organization (WHO) $[2,3]$. Person-to-person transmission had been reported twice by the United Kingdom (UK) and may also have occurred in two family clusters in Saudi Arabia (SA) and a hospital cluster in Jordan [2-4]. Fifteen confirmed cases have presented with severe acute respiratory infection (SARI), in some cases accompanied by acute renal failure [5-7]. Eleven patients have died [3]. One confirmed contact case in the UK and one confirmed case in SA presented with mild illness, and the clinical manifestations also appeared milder in unconfirmed but probable cases in the hospital cluster in Jordan $[2-4,8]$. It is important to understand the full spectrum of illness associated with this new human infection, and to determine how that relates to infectivity and the ability to transmit the virus, as well as to outcomes of diagnostic tests.

The emergence of this novel hCoV lead to an international collaborative laboratory response resulting in the rapid availability of diagnostic real-time reverse transcription polymerase chain reaction (RT-PCR) assays [9-11]. Successful use of PCR-based diagnostics relies on timing and technique of sampling, with knowledge about kinetics of viraemia and shedding of virus during the course of infection. Investigations into epidemiologically linked clinical cases in SA and Jordan demonstrated that not in all symptomatic patients within a cluster viral RNA could be detected by RT-PCR, similar to what has been described for SARS and other infectious diseases $[2,11]$. For diagnosis of hCoV-EMC infection, virus detection by RT-PCR during the acute phase may be less sensitive, as samples from the lower respiratory tracts (tracheal aspirates, bronchoalveolar lavage) are necessary for optimal detection, and these are not as readily available as upper respiratory tract samples $[1,6,12]$. Therefore, serological testing is imperative to complement RT-PCR findings for adequate diagnosis. In addition serology is essential for the monitoring of the evolution of an outbreak, including (retrospective) studies of asymptomatic and mild cases and identification of animal reservoirs. [13-16].

Currently an immunofluorescence assay (IFA) using hCoV-EMC-infected cells is available [10]. However, as the authors caution, this assay may generate falsepositive results due to the global co-circulation of four hCoVs namely hCoV-NL63, hCoV-OC 43, hCoV-229E and hCoV-HKU1. Cross-reactivity to conserved viral proteins limits the use of such whole virus-based IFAs, especially as antibodies against coronaviruses within a genus are generally known to cross-react $[2,17]$. Therefore, the European Centre for Disease Prevention and Control (ECDC) advised not to screen patients by whole virus IFA unless second stage serology is conducted [2]. For confirmation, virus neutralisation assays are the gold standard, but these are difficult to 
implement and not widely available. Therefore, there is a need for alternative methods.

Here, we describe the use of antigen-microarrays to measure antibodies directed against the receptorbinding spike domain $\mathrm{S}_{1}$ of hCoV- EMC and SARS$\mathrm{CoV}$. The most variable immunogenic CoV antigen is the amino-terminal $\mathrm{S}_{1}$ subunit of the spike protein, which exhibits at most some $30 \%$ amino acid identity between human CoV isolates (data not shown). We describe a specific serological tool, distinguishing cross-reactivity with the four common hCoVs belonging to the same genus as hCoV-EMC and SARS-CoV (genus Betacoronavirus, hCoV-OC43, hCoV-HKU1), and to the genus Alphacoronavirus (hCoV-NL63 and hCoV-229E).

\section{Methods}

\section{Protein expression}

Plasmids encoding the amino-terminal receptor-binding spike domain $\mathrm{S}_{1}$ of hCoV-EMC and SARS-CoV, fused to the Fc part of human IgG, were expressed in HEK293 T cells, and S1-Fc proteins were purified from the culture supernatant by protein A chromatography as described [18]. Purified S1-Fc was cleaved by thrombin at the $\mathrm{S}_{1}-\mathrm{Fc}$ junction. Soluble $\mathrm{S}_{1}$ was subsequently purified by gel-filtration chromatography and concentrated using Amicon Ultra-0.5 filter (Merck, Darmstadt, Germany).

\section{Preparation and testing of microarrays}

Purified hCoV-EMC S1 and SARS-CoV S1 were spotted in quadruplicate in two drops of $333 \mathrm{pL}$ each in a twofold dilution series ranging from $1: 2$ to $1: 8$ (starting at $200 \mu \mathrm{g} / \mathrm{mL}$ for undiluted antigen) on 16-pad nitrocellulose-coated slides (Fast Slides, Maine Manufacturing, Grand Blanc, US) using a non-contact Piezorray spotter (PerkinElmer, Waltham, US) as described earlier [19]. Slides were pre-treated with Blotto blocking buffer to avoid non-specific binding as described [19]. Dilutions of serum in Blotto containing $0.1 \%$ Surfact-Amps 20 (Thermo Fisher Scientific Inc. Breda, the Netherlands) were transferred in a volume of $90 \mu \mathrm{L}$ to the slides and incubated for $1 \mathrm{~h}$ at $37^{\circ} \mathrm{C}$ in a moist chamber. Sera tested for the presence of IgM were treated with GullSORB (Meridian Bioscience Inc., Cincinnati, US) to eliminate rheumatoid factor and immune IgG, which can interfere with IgM assays. Upon washing, goat anti-human IgG (Fc-fragment specific) or IgM (Fc5 $\mu$ fragment specific) conjugated with DyLight649 fluorescent dye (Jackson Immuno Research, West Grove, US) was incubated for $1 \mathrm{~h}$ at $37^{\circ} \mathrm{C}$ in a moist chamber. After washing with buffer and water, the slides were dried. Fluorescence signals were quantified by a ScanArray Gx Plus microarray scanner (PerkinElmer) using an adaptive circle (diameter 80-200 $\mu \mathrm{m}$ ) with a saturated signal at 65,535. Median spot fluorescence foreground intensity (background subtracted) was determined using ScanArray Express vs 4.0 software.
Sera

For validation experiments the following serum samples were used. All sera were stored at $-20{ }^{\circ} \mathrm{C}$ or $80^{\circ} \mathrm{C}$ prior to testing.

- Anonymised serum samples from 72 persons ranging in age from o year to 95 years sampled during 2008. These sera had been sent to the Dutch National Institute for Public Health and the Environment (RIVM) for routine Bordetella pertussis serology and thus represented a cohort biased towards patients with non-influenza-like respiratory symptoms. Anonymised use of serum from RIVM was covered by the rules of the code of conduct for proper use of human tissue of the Dutch Federation of Medical Scientific Associations.

- Anonymised serum samples of 10 children, ages ranging from 9 to 14 months, known to be positive for antibodies to one of the four common hCoVs, as determined by comparative ELISA using $\mathrm{N}$ antigen at a dilution factor of 1:200 [20,21]. Samples were obtained in 2001 , were stored at $-80^{\circ} \mathrm{C}$ and were chosen from this age group because antibodies at this age most likely result from single exposures [21]. Two hCoV-HKU1, two hCoV-OC43, three hCoV-229E and three hCoV-NL63 IgG positive sera were used.

- Three anonymised hCoV-OC43-positive sera (including one paired sample) from patients with virologically (PCR) and serologically (IgG IFA) confirmed infection, and one hCoV-OC43 IgG positive serum as described in [22].

- Serum samples from two cynomolgus macaques infected with hCoV-EMC (virus stock obtained as described [23]) taken at 28 days post infection, including a pre-infection serum.

- A serum sample from a rabbit immunised with hCoVEMC S1 taken 28 days post immunisation, including a pre-immunisation serum.

- One serum sample from an hCoV-EMC infected patient who was treated for SARI in a hospital in Essen, Germany taken at day 20 after onset of illness. This serum had an IgG titre of 1:10,000 and an IgM titre of 1:1,000 as determined by IFA on cells infected with hCoV-EMC and an IgM and IgG titre of $>1: 320$ as determined by IFA on cells expressing recombinant $S$ protein $[10,22,23]$.

- Convalescent serum samples from two SARS-CoV infected patients. Serum SARS-1 was taken 3.5 years after disease. It had an IgG titre of 1:160 and no IgM titre as determined by IFA on cells expressing recombinant S protein [22]. Serum SARS-2 was taken 36 days after onset of illness with an IgG titre of 1:1,000 in IFA and 1:1,600 in ELISA. No IgM titre was found by IFA (personal communication, M. Niedrig, March 2013).

- Convalescent serum samples of three patients with severe respiratory complaints who had travelled to SA, Dubai and Dubai/Qatar within 10 days before onset of illness, and therefore had been tested to exclude hCoV-EMC by RT-PCR, as recommended by WHO. 


\begin{tabular}{|c|c|c|c|c|c|}
\hline \multirow[b]{2}{*}{ Sera } & \multirow[b]{2}{*}{ Number } & \multicolumn{2}{|c|}{ hCoV-EMC Ag ${ }^{a}$} & \multicolumn{2}{|c|}{ SARS-CoV Ag ${ }^{a}$} \\
\hline & & $\lg G$ & $\lg M$ & $\lg G$ & $\lg M$ \\
\hline \multicolumn{6}{|l|}{ Human } \\
\hline Population sera human & 72 & Negative & Negative & Negative & Negative \\
\hline hCoV-OC43 human & 6 & Negative & Negative & Negative & Negative \\
\hline hCoV-229E human & 3 & Negative & Negative & Negative & Negative \\
\hline hCoV-NL63 human & 3 & Negative & Negative & Negative & Negative \\
\hline hCoV-HKU1 human & 2 & Negative & Negative & Negative & Negative \\
\hline hCoV-EMC human & 1 & Positive & Positive & Negative & Negative \\
\hline SARS-CoV human & 2 & Negative & Negative & Positive & Negative \\
\hline \multicolumn{6}{|l|}{ Animal } \\
\hline Pre-immunisation rabbit & 1 & Negative & Not tested & Negative & Not tested \\
\hline hCoV-EMC post-immunisation rabbit & 1 & Positive & Not tested & Negative & Not tested \\
\hline Pre-infection macaque & 1 & Negative & Not tested & Negative & Not tested \\
\hline hCoV-EMC post-infection macaque & 2 & Positive & Not tested & Negative & Not tested \\
\hline
\end{tabular}

Ag: S1 antigen.

${ }^{a}$ Reactivity was scored based on the arbitrary set cut-off.

All human sera were collected in accordance with the ethical principles set out in the declaration of Helsinki; Macaque and rabbit sera were collected in compliance with Dutch laws on animal handling and welfare.

\section{Results}

\section{Testing antigen quality}

The amino-terminal receptor-binding spike domains $\mathrm{S}_{1}$ of hCoV-EMC and SARS-CoV were spotted in serial dilutions $(1: 2-1: 8)$ on nitrocellulose slides and incubated with two-fold serial dilutions (1:20-1:640) of sera from hCoV-EMC-infected macaques, a rabbit immunised with hCoV-EMC S1, or a SARS-CoV-infected patient. All sera showed high-level IgG reactivity with their homologous $\mathrm{S}_{1}$ antigen, while only background reactivity was observed with the heterologous antigen. Pre-immune serum of macaque and rabbit were non-reactive (Table). Based on these observations it was concluded that the antigens as printed on the array slides were intact and in the proper conformation for immuno-reactivity with homologous antibodies.

\section{Validation of protein array}

To analyse the specificity of the microarray for detection of hCoV-EMC and SARS-CoV IgM and IgG antibodies, the reactivity of a cohort of human sera submitted to the RIVM for whooping cough diagnostics was tested. The cohort consisted of 72 sera of nonexposed patients, ranging from $0-95$ years of age. This cohort represents the putative cross-reacting potential in the Dutch population, where previous studies have shown high seroprevalences for one or more of the four common hCoVs $[20,21]$. The sera were tested for IgM and IgG reactivity with the hCoV-EMC and SARS$\mathrm{CoV}$ antigens at dilutions 1:20 and 1:40 (Table, Figure 1). The observed reactivity was low. Based on these results an arbitrary cut-off was set at 5,000 for IgM and at 10,000 for IgG measurements.

The specificity of the microarray was confirmed using serum samples from children with known recent exposure and antibody responses to one of the four common hCoVs, including the betacoronaviruses $\mathrm{OC}_{43}$ and HKU1. Sera were tested at dilutions 1:20 and 1:160, with one serum for each hCoV tested in a two-fold dilution series of $1: 20$ to $1: 640$. None of the 14 sera showed reactivity above background, for either IgG or IgM, with the hCoV-EMC and SARS-CoV antigens (Table, Figures 1 and 2).

Subsequently, the array was tested with a single serum sample taken in the third week of illness of a patient infected with hCoV-EMC [22], and convalescent serum samples of two patients taken during the SARS-CoV epidemic. The serum of the hCoV-EMC patient showed a clear positive reactivity for IgG with EMC $S_{1}$ in the dilution range from 1:20 to $1: 20,480$, declining only at dilutions 1:5,120 and higher. The IgM reactivity of the hCoV-EMC serum with EMC antigen was saturated in the dilution range from 1:20 to 1:80, with declining, but clearly positive, levels of reactivity at higher dilutions. No reactivity was observed with SARS antigen for either IgG or IgM. 


\section{FIGURE 1}

IgM and IgG reactivity of two-step serially diluted sera with hCoV-EMC S1- and SARS-CoV S1-spotted microarrays (n=89)
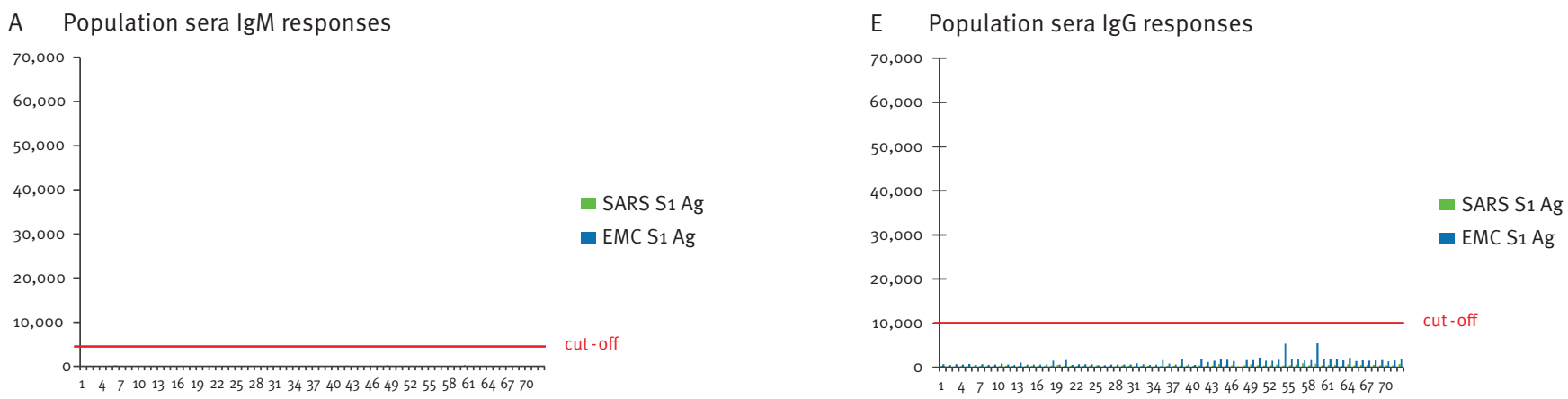

B $\quad E M C$ - specific serum IgM titration

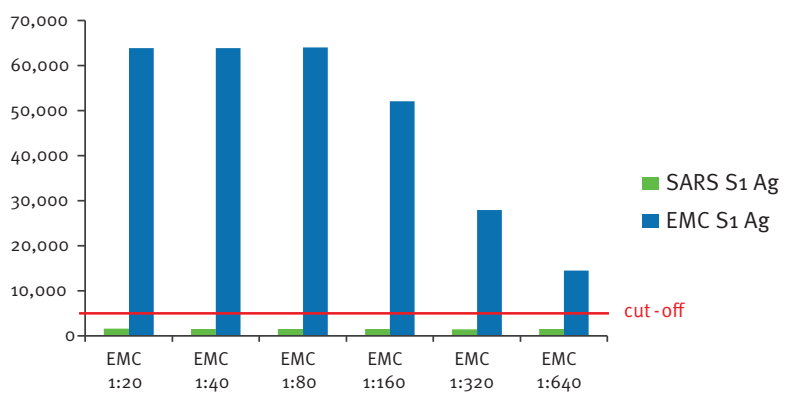

F $\quad$ EMC - specific serum IgG titration

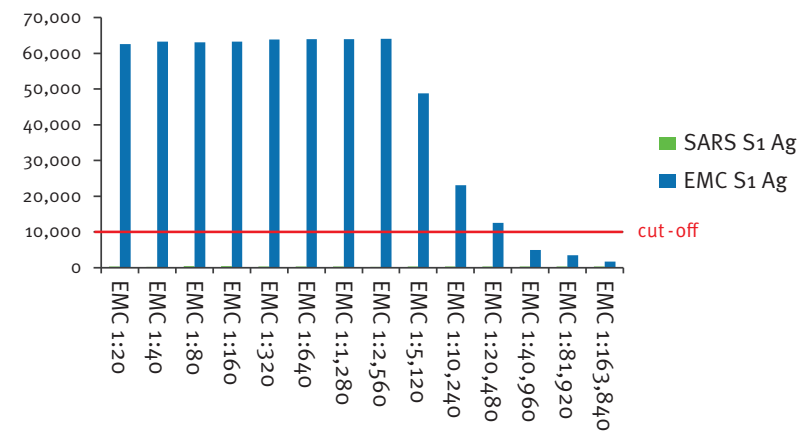

C SARS - specific serum IgM titration

G SARS - specific serum IgG titration
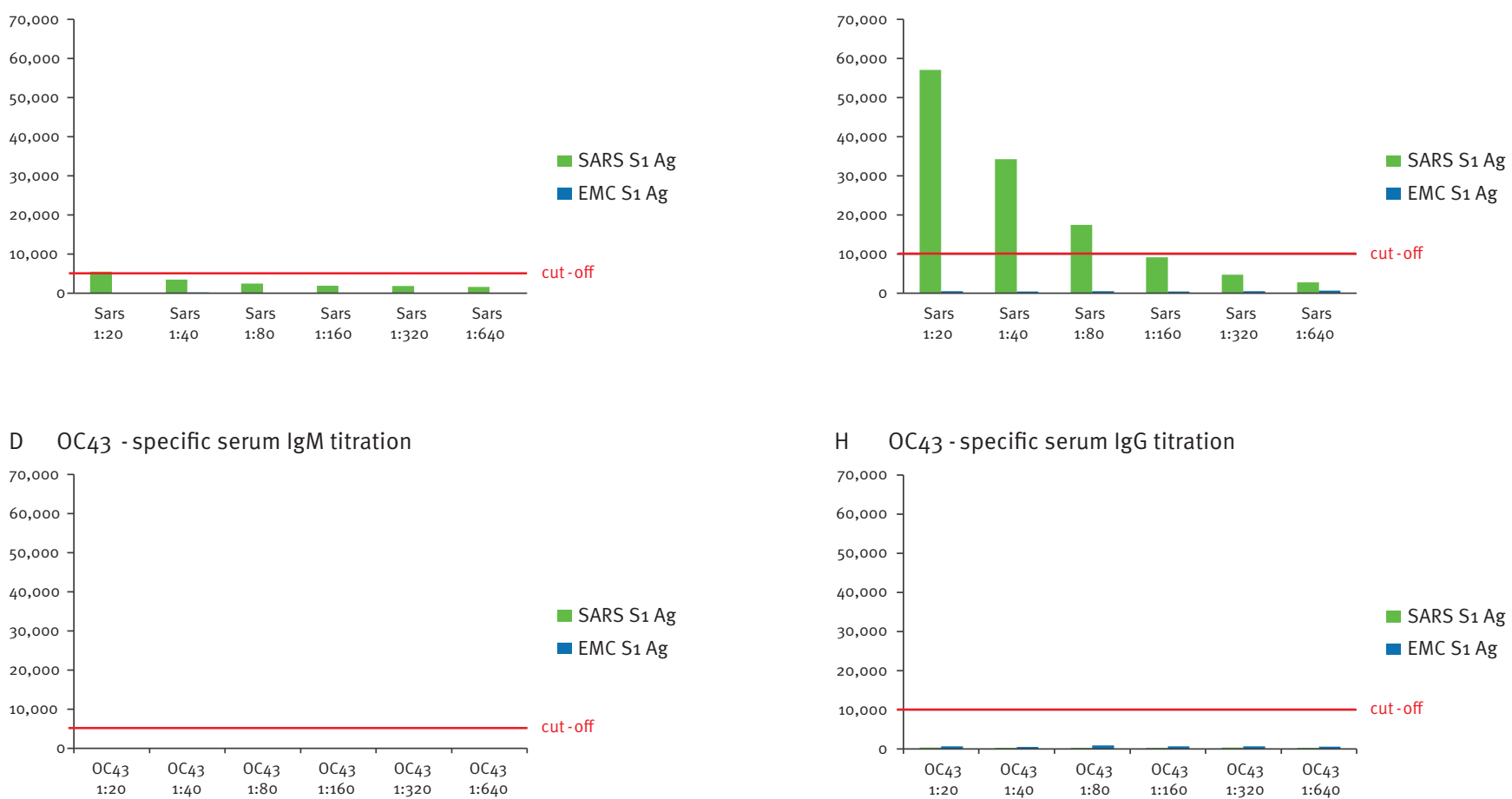

Sera: 72 population sera 1:20 diluted (panel A (IgM) and E (IgG)), hCoV-EMC (panel B (IgM) and F (IgG)), SARS-CoV serum SARS-1 (panel C (IgM) and $\mathrm{G}(\operatorname{IgG})$ ) and hCoV-OC43 (panel D (IgM) and H (IgG)). Panels $\mathrm{C}$ and $\mathrm{G}$ are representative for all SARS-CoV sera tested $(n=2)$. Panels $D$ and $\mathrm{H}$ are representative for all common hCoV sera tested $(n=14)$.

$\mathrm{X}$-axes denote serum numbers (panel $\mathrm{A}$ and $\mathrm{E}$ ) or serum dilutions: two-step serial dilutions, staring dilution 1:20.

$\mathrm{Y}$-axes denote the measured median spot foreground fluorescence intensities. 
Representative pictures of the protein microarray analysis of convalescent sera from patients infected with the six known hCoVs $(\mathrm{n}=17)$
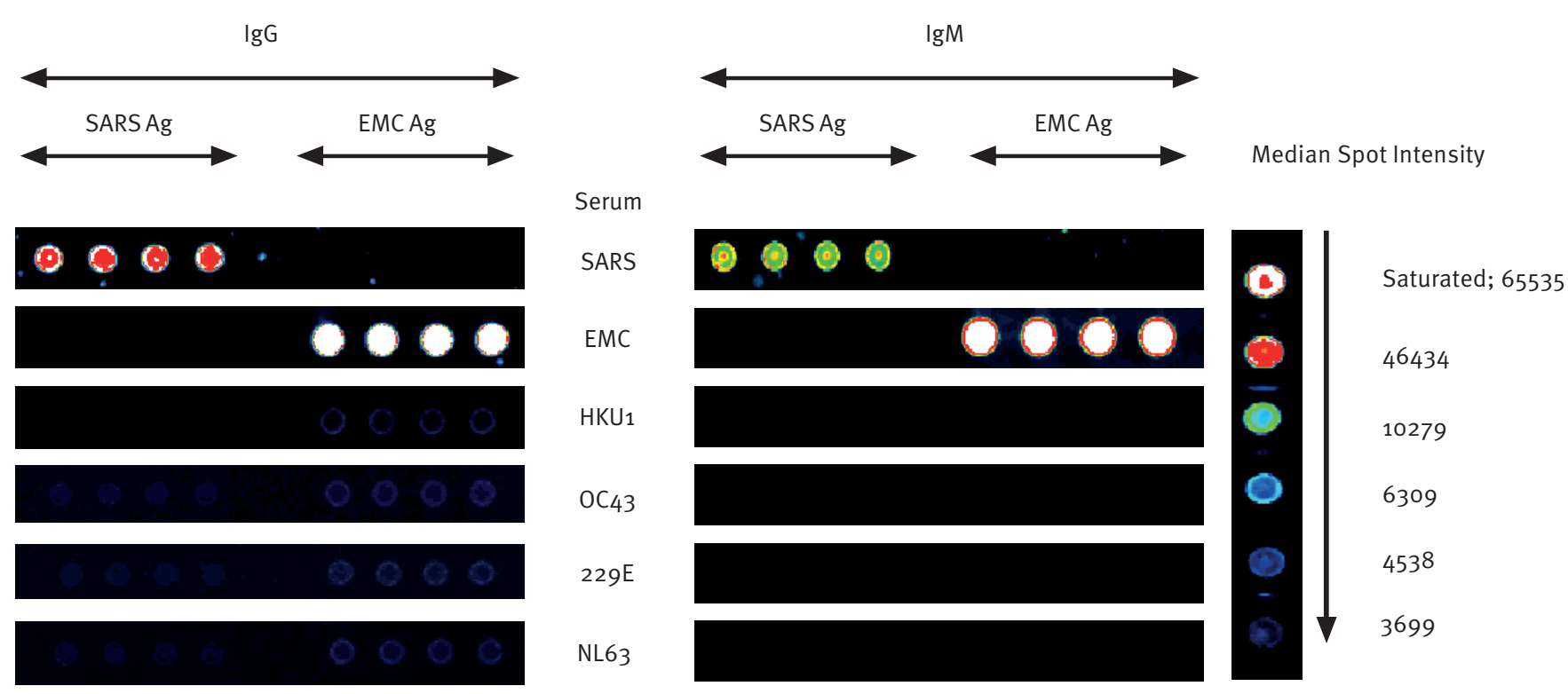

Ag: antigen.

Vertically from top to bottom: Incubation with sera containing antibodies to SARS-CoV, hCoV-EMC, hCoV-HKU1, hCoV-OC43, hCoV-229E or hCoV-NL63.

IgG (left panel) and IgM (right panel) reactivity of the six sera to SARS-CoV and hCoV-EMC S1 protein (SARS Ag and EMC Ag respectively). Colours reflect median spot intensity as shown in the legend on the right.

Antigens spotted in quadruplicate with dilution factor 1:2; sera dilution factor 1:20.

The two SARS-CoV sera SARS-1 and SARS-2 gave a clear positive reaction with the SARS antigen for IgG at dilutions from 1:20 to $1: 80$ and from 1:20 to $1: 160$, respectively, with no reactivity for IgM using the chosen cut-off. No reactivity was observed with the EMC antigen (Table, Figures 1 and 2).

\section{Serological diagnosis}

Convalescent sera from three patients with severe respiratory symptoms and a travel history to the Middle East were tested using the newly developed microarray. None of the patients showed positive reactivity for IgM or IgG with EMC-S1.

\section{Discussion}

We present a protein microarray-based serological test for the confirmation of hCoV-EMC and SARS-CoV infections. A major obstacle in the development of detection tools for novel, emerging viruses is the availability of sufficient, well-defined negative and positive sera for the assessment of the specificity and sensitivity of the assays. Nevertheless, results so far suggest that our microarray is highly specific for the detection of IgM and IgG antibodies against these emerging hCoVs, with no false-positive reactivity in 72 population sera and 14 sera known to be positive for one of the four widely circulating hCoVs - OC43, -HKU1, $-229 \mathrm{E}$ and -NL63. Samples with a high titre were preferred for assay validation, but the exact titres of the antibodies against the common hCoVs in the latter validation cohort were not known.

However, previous studies from the Netherlands have found that by the age of 30 months, more than $50 \%$ of children seroconverted to one or more of the alpha(hCoV-NL63, hCoV-229E) or betacoronaviruses (hCoV$\mathrm{OC}_{43}, \mathrm{hCoV}-\mathrm{HKU}_{1}$ ), and seropositivity reached $100 \%$ by 10 years of age for alphacoronaviruses $[20,21]$. The seroprevalence for betacoronaviruses was not specifically tested in the Netherlands, but found to be $91 \%$ in adults in the United States [24]. Therefore, the absence of false-positives in our population samples is strong evidence for the specificity of the method. IgG and IgM antibodies to hCoV-EMC and IgG to SARS-CoV were clearly detectable in positive patient sera. However, due to the small number of available positive patient sera, determination of the sensitivity of the assay in relation to viral load, clinical manifestation and phase 
of infection requires further investigation. For this essential clinical validation, international sharing of positive sera by (national) laboratories in possession of such sera is a prerequisite.

Currently, WHO and ECDC recommend the collection of paired serum samples, preferably from the acute and convalescent phase, of all cases under investigation, as serological testing might be necessary to confirm infection when clinical presentation and epidemiology suggest an infection with hCoV-EMC despite negative $P C R$ results $[2,12]$. In addition, serology is needed for contact investigations and source tracking. A twostaged serological approach is recommended, which proved effective in a contact investigation of an hCoVEMC infection treated in Germany. It uses IFA with virus-infected cells for screening, and as second-stage recombinant spike- and nucleocapsid-transfected cells and virus neutralisation tests [22]. Our protein microarray enables specific, one-stage, high-throughput testing, with the benefit of minimal sample requirement. This technique can use dried blood spots for testing, which greatly facilitates shipping of samples.

The serological assay presented here is available and of great value for human and animal population screening, both of which are necessary to gain insight in the epidemiology of the novel hCoV. The array format can be modified to identify primary and intermediate animal reservoirs by simple adaptation of the conjugate used to visualise reactivity on the array (data not shown). Our assay is available to aid diagnosis in individual patients, for confirmatory testing of positive tests and for (large-scale) contact studies.

\section{Acknowledgements}

We are grateful to Matthias Niedrig (Robert Koch Institute, Berlin, Germany) and Jürg Timm (University of DuisburgEssen, Essen, Germany) for provision of a SARS-CoV serum and the hCoV-EMC patient serum. Johan Reimerink is acknowledged for his input in discussions. We thank Dorian Stolk, Joëlle Reijm, Mariëlle Zonneveld, Amber van Broekhoven and Maarten F. Jebbink for hCoV-NL63-, hCoV$229 \mathrm{E}-$, hCoV-HKU1-, and hCoV-OC43-specific sera selection assays.

RdS was funded by the European Public Health Microbiology Training Program (EUPHEM), ECDC, Stockholm. LvdH, BH and $\mathrm{AO}$ were funded by the European Union $\mathrm{FP}_{7}$ project EMPERIE (contract number 223498).

Conflict of interest

None declared.

Authors' contributions

CR: assisted in designing the study, coordinated the study, analysed data, wrote manuscript. HM: performed laboratory testing and serum production. GJG: assisted in designing the study, performed laboratory testing, analysed data, read and revised manuscript. LvdH: performed laboratory testing, provided sera, read and revised manuscript. BM: performed laboratory testing, read and revised manuscript.
MM: provided sera, performed laboratory testing, read and revised manuscript. $\mathrm{BH}$ : serum production, read and revised manuscript. RdS: assisted in study design, read and revised the manuscript.NS: performed laboratory testing and serum production. UD: provided sera, read and revised manuscript. PR: read and revised the manuscript. AO: provided sera, read and revised the manuscript. $C D$ : provided sera, read and revised the manuscript. BJB: produced design antigen, provided antigens and serum, read and revised the manuscript. MK: assisted in designing the study, analysed data, read and revised the manuscript. 


\section{References}

1. Zaki AM, van Boheemen S, Bestebroer TM, Osterhaus AD, Fouchier RA. Isolation of a novel coronavirus from a man with pneumonia in Saudi Arabia. N Engl J Med. 2012;367(19):181420. http://dx.doi.org/10.1056/NEJMoa1211721. PMid:23075143.

2. European Centre for Disease prevention and Control (ECDC). Severe respiratory disease associated with a novel coronavirus. Rapid Risk Assesment. Stockholm: ECDC; Feb 2013. [Accessed 19 Feb 2013]. Available from: http://www.ecdc. europa.eu/en/publications/Publications/novel-coronavirusrapid-risk-assessment-update.pdf

3. European Centre for Disease prevention and Control (ECDC). Confirmed cases of novel coronavirus infection $(n=17)$ reported worldwide as of 26 March 2013. Stockholm: ECDC [Accessed 2 Apr 2013]. Available from: http://www.ecdc. europa.eu/en/healthtopics/Documents/Novel-coronaviruscases-table.pdf

4. Pebody RG. The Health Protection Agency (HPA) UK Novel Coronavirus Investigation team. Evidence of personto-person transmission within a family cluster of novel coronavirus infections, United Kingdom, February 2013. Euro Surveill. 2013;18(11):pii=20427. Available from: http://www. eurosurveillance.org/ViewArticle.aspx?Articleld=20427

5. Albarrak AM, Stephens GM, Hewson R, Memish ZA. Recovery from severe novel coronavirus infection. Saudi Med J. 2012;33(12):1265-9. PMid:23232672.

6. Bermingham A, Chand MA, Brown CS, Aarons E, Tong C, Langrish $C$, et al. Severe respiratory illness caused by a novel coronavirus, in a patient transferred to the United Kingdom from the Middle East, September 2012. Euro Surveill. 2012;17(40): pii=20290. Available from: http://www. eurosurveillance.org/ViewArticle.aspx?Articleld $=20290$

7. Pebody RG, Chand MA, Thomas HL, Green HK, Boddington NL, Carvalho C, et al. The United Kingdom public health response to an imported laboratory confirmed case of a novel coronavirus in September 2012. Euro Surveill. 2012;17(40): $\mathrm{pii}=20292$. Available from: http://www.eurosurveillance.org/ ViewArticle.aspx?Articleld $=20292$

8. ProMED-mail. Novel coronavirus-East.Med. (7): Saudi Arabia, UK, Germany. ProMED mail. Archive number: 20130221.1554109. 21 Feb 2013. Available from: http://www. promedmail.org/ ?archiveid $=20130221$

9. Corman VM, Eckerle I, Bleicker T, Zaki A, Landt O, EschbachBludau M, et al. Detection of a novel human coronavirus by real-time reverse-transcription polymerase chain reaction. Euro Surveill. 2012;17(39):pii=20285. Available from: http:// www.eurosurveillance.org/ViewArticle.aspx?Articleld $=20285$

10. Corman V, Muller M, Costabel U, Timm J, Binger T, Meyer $B$, et al. Assays for laboratory confirmation of novel human coronavirus (hCoV-EMC) infections. Euro Surveill. 2012;17(49):pii=20334. Available from: http://www. eurosurveillance.org/ViewArticle.aspx?Articleld=20334

11. Palm D, Pereyaslov D, Vaz J, Broberg E, Zeller H, Gross D, et al. Laboratory capability for molecular detection and confirmation of novel coronavirus in Europe, November 2012. Euro Surveill. 2012;17(49): pii=20335. Available from: http://www. eurosurveillance.org/ViewArticle.aspx?Articleld =20335

12. World Health Organization (WHO). Laboratory testing for novel coronavirus. Interim recommendations. Geneva: WHO; 21 Dec 2012. [Accessed 14 Mar 2013]. Available from: http://www.who. int/csr/disease/coronavirus_infections/LaboratoryTestingNove ICoronavirus_21Dec12.pdf

13. Ng LF, Wong M, Koh S, Ooi EE, Tang KF, Leong HN, et al. Detection of severe acute respiratory syndrome coronavirus in blood of infected patients. J Clin Microbiol. 2004;42(1):34750. http://dx.doi.org/10.1128/JCM.42.1.347-350.2004 PMCid:321706.

14. Chen W, Xu Z, Mu J, Yang L, Gan H, Mu F, et al. Antibody response and viraemia during the course of severe acute respiratory syndrome (SARS)-associated coronavirus infection. J Med Microbiol. 2004;53(Pt 5):435-8. Epub 2004/04/21.

15. Guan Y, Zheng BJ, He YQ, Liu XL, Zhuang ZX, Cheung CL, et al. Isolation and characterization of viruses related to the SARS coronavirus from animals in southern China. Science. 2003;302(5643):276-8. http://dx.doi.org/10.1126/ science.1087139. PMid:12958366.

16. Prevalence of IgG antibody to SARS-associated coronavirus in animal traders--Guangdong Province, China, 2003. MMWR Morb Mortal Wkly Rep. 2003;52(41):986-7. PMid:14561956.

17. Novel human Coronavirus HCoV-EMC. Recommendations regarding serological testing. Bonn: Institut für Virologie; 2013. [Accessed 21 Feb 2013]. Available from: http://www. virology-bonn.de/index.php?id=40

18. Raj VS, Mou H, Smits SL, Dekkers DH, Muller MA, Dijkman $\mathrm{R}$, et al. Dipeptidyl peptidase 4 is a functional receptor for the emerging human coronavirus-EMC. Nature. 2013;495(7440):251-4. http://dx.doi.org/10.1038/nature12005. PMid:23486063.

19. Koopmans M, de Bruin E, Godeke GJ, Friesema I, van Gageldonk R, Schipper M, et al. Profiling of humoral immune responses to influenza viruses by using protein microarray. Clin Microbiol Infect. 2012;18(8):797-807. http://dx.doi. org/10.1111/j.1469-0691.2011.03701.x. PMid:22212116.

20. Dijkman R, Jebbink MF, El Idrissi NB, Pyrc K, Muller MA, Kuijpers TW, et al. Human coronavirus NL63 and 229E seroconversion in children. J Clin Microbiol. 2008;46(7):2368 73. http://dx.doi.org/10.1128/JCM.00533-08. PMid:18495857. PMCid:2446899.

21. Dijkman R, Jebbink MF, Gaunt E, Rossen JW, Templeton KE, Kuijpers TW, et al. The dominance of human coronavirus $\mathrm{OC}_{43}$ and NL63 infections in infants. J Clin Virol. 2012;53(2):135-9. http://dx.doi.org/10.1016/j.jcv.2011.11.011. PMid:22188723.

22. Buchholz U, Müller MA, Nitsche A, Sanewski A, Wevering N, Bauer-Balci T, et al. Contact investigation of a case of human novel coronavirus infection treated in a German hospital, October-November 2012. Euro Surveill. 2013;18(8): pii=20406. Available from: http://www.eurosurveillance.org/ViewArticle. aspx?Articleld=20406. PMid:23449231.

23. van Boheemen S, de Graaf M, Lauber C, Bestebroer TM, Raj VS, Zaki AM, et al. Genomic characterization of a newly discovered coronavirus associated with acute respiratory distress syndrome in humans. MBio. 2012;3(6): pii: e0047312. http://dx.doi.org/10.1128/mBio.00473-12. PMid:23170002 PMCid:3509437.

24. Severance EG, Bossis I, Dickerson FB, Stallings CR, Origoni $A E$, Sullens A, et al. Development of a nucleocapsid-based human coronavirus immunoassay and estimates of individuals exposed to coronavirus in a U.S. metropolitan population. Clin Vaccine Immunol. 2008;15(12):1805-10. http://dx.doi. org/10.1128/CVI.00124-08. PMid:18945884 PMCid:2593164 